\title{
Immunogenicity Specimen Assessments Character Result in Standard Format
}

National Cancer Institute

\section{Source}

National Cancer Institute. Immunogenicity Specimen Assessments Character Result in

Standard Format. NCI Thesaurus. Code C117561.

The standard character or string for representation and reporting of immunogenicity specimen assessment data. 